\title{
DENGUE NEONATAL EN EL PERÚ: REPORTE DE UN CASO
}

\author{
Hermann Silva Delgado 1,2,a, Juan Carlo Ruiz Ríos ${ }^{1, b}$, Erick Leray Vela Barbarán ${ }^{1, c}$, Deicy Rengifo del \\ Aguila $^{1, d}$, María García M. ${ }^{3, e}$, Luis Rodríguez Benavides ${ }^{4, f}$, Alberto Mendoza-Ticona ${ }^{3,9}$
}

\begin{abstract}
RESUMEN
Se presenta el caso de un neonato de sexo femenino, a término, producto de madre fallecida al séptimo día de su puerperio, por falla multiorgánica debido a dengue grave confirmado por detección de antígeno NS1 e lgM. La recién nacida (RN) no tuvo complicaciones, pero a partir del cuarto día de vida desarrolló fiebre, ictericia, manifestaciones de extravasación de plasma, hepatomegalia, ascitis, plaquetopenia y otros signos de síndrome de respuesta inflamatoria sistémica. Su evolución final fue favorable con tratamiento instaurado. Se demuestra con PCR en tiempo real, la presencia del virus dengue serotipo 2 en sangre de la RN, confirmándose el primer caso de dengue neonatal reportado en el Perú.
\end{abstract}

Palabras clave: Dengue; Recien Nacido; Embarazo; Transmisión Vertical de Enfermedad Infecciosa; Perú (fuente: DeCS BIREME).

\section{NEONATAL DENGUE IN PERU : A CASE REPORT}

\begin{abstract}
We present the case of a full-term female newborn, whose mother died seven days postpartum from multi-organ failure due to severe dengue confirmed by NS1 antigen detection and positive IgM. The newborn did not have any complication, but at the fourth day of life she developed fever, jaundice, signs of plasma leakage, thrombocytopenia, hepatomegaly, ascitis, and others signs of systemic inflammation response syndrome. She fully recovered with supportive treatment. The RT-PCR test of a peripheral blood sample revealed a positive result for the dengue virus serotype 2, confirming the first case of neonatal dengue reported in Peru.
\end{abstract}

Key words: Dengue; Infant, Newborn; Pregnancy; Infectious Disease Transmission, Vertical; Peru (source: MeSH NLM)

\section{INTRODUCCIÓN}

La región Loreto se ubica entre los 100 y 150 m.s.n.m. en la Amazonía peruana. Iquitos, su ciudad capital, ha experimentado epidemias de enfermedad febril causada por la subsecuente invasión de virus del dengue (DENV): DENV-1 en 1990 - 1991, una variedad Americana de DENV-2 en 1995, DENV-3 en el 2001, una variedad Asiática de DENV-2 en el 2002 y DENV-4 en el 2008. (1, 2) La curva endémica característica de cada año presenta un marcado incremento de casos entre la semana epidemiológica 42 hasta la semana 10 del siguiente año. ${ }^{(3)}$ En las últimas semanas del año 2010 se declaró la epidemia de dengue en lquitos al sobrepasar la zona de alerta del canal endémico. El Instituto Nacional de Salud de Perú (INS) evidenció la presencia del genotipo III del DENV-2, variante asiática-americana ${ }^{(4)}$ lo que se correlacionó con el mayor reporte de casos de dengue grave y muertes que se noti- ficaron en lquitos en las primeras semanas de 2011. Esta variedad de DENV-2 se ha asociado a brotes explosivos con casos graves en la región amazónica de Brasil. (5)

En este contexto epidemiológico, el presente reporte describe, según nuestro conocimiento, el primer caso de dengue neonatal documentado en el Perú, lo cual demuestra la transmisión vertical del DENV-2 tipificada en el producto de la gestación, destaca las enseñanzas relevantes para mejorar nuestro enfoque de diagnóstico y manejo de las gestantes y sus productos, con el objeto de prevenir casos similares durante brotes de dengue.

\section{PRESENTACIÓN DE CASO}

Recién nacida de madre de 21 años, segundigesta y sin antecedentes patológicos de consideración. Cuatro días

\footnotetext{
Cuidados Intensivos Neonatales, Servicio de Neonatología Hospital Apoyo lquitos.

2 Facultad de Medicina, Universidad Nacional de la Amazonía Peruana.

3 Centro Nacional de Salud Pública, Instituto Nacional de Salud.

4 Dirección Regional de Salud de Loreto.

a Doctor en Medicina; ${ }^{\mathrm{b}}$ Médico Cirujano; ${ }^{\mathrm{C}}$ Interno de Medicina; ${ }^{\mathrm{a}}$ Enfermera; ${ }^{\text {e }}$ Tecnóloga médica; ${ }^{\mathrm{f}}$ Médico epidemiólogo; ${ }^{9}$ Médico infectólogo epidemiólogo.
} 
antes de parto la madre acude al servicio de emergencia del Hospital de Apoyo de lquitos por presentar fiebre de un día de evolución catalogado como cuadro febril indiferenciado, siendo dada de alta. Retorna al cuarto día por rotura prematura de membranas, afebril, se detectó oligohidramnios severo y sufrimiento fetal agudo. Se decide parto por cesárea de urgencia donde se detecta líquido serohemático libre en cavidad peritoneal y sangrado en napa de lecho y herida operatoria asociada con plaquetopenia severa. Pasa a unidad de cuidados intensivos y a los dos días desarrolla falla orgánica múltiple y coagulación intravascular diseminada. En una muestra de sangre al quinto día de puerperio, se le diagnostica dengue grave confirmado por la detección de antígeno NS1 positivo por prueba ELISA captura, Panbio dengue (Inverness Medical, Australia) e IgM e Ig G por prueba de ELISA captura, Tariki-dengue (INS, Lima Perú). EI PCR en tiempo real de la misma muestra fue negativo. La paciente no es referida a un establecimiento de mayor complejidad del Ministerio de Salud y fallece al séptimo día de su puerperio.

La recién nacida $(R N)$ tuvo una edad gestacional de 37 semanas por test de Capurro, con puntuación de APGAR de 4 al minuto y 8 a los 5 minutos, sin requerir maniobras de resucitación. Tuvo bajo peso al nacer con $2235 \mathrm{~g}$, otras mediciones somatométricas estuvieron en rango normal. El examen físico inicial no reveló anormalidades. Cursó asintomática durante los tres primeros días. Al cuarto día presenta ictericia y fiebre de $38{ }^{\circ} \mathrm{C}$, por lo que es internada en cuidados intermedios, recibe fototerapia y se diagnostica incompatibilidad $\mathrm{ABO}$ (madre grupo $\mathrm{O}+$, recién nacida grupo $\mathrm{A}+$ ) y síndrome de respuesta inflamatoria por probable foco infeccioso, se inicia tratamiento con ampicilina y amikacina. Los valores de hematometría y bioquímica iniciales y sucesivos se presentan en la Tabla 1. Al quinto día presenta hipoglicemia severa, continúa febril $\left(38,4{ }^{\circ} \mathrm{C}\right)$ con episodios de escalofríos, piel eritematosa con acrocianosis, frialdad distal, inicia distensión abdominal con dolor a la palpación y hepatomegalia. Una prueba de proteína $\mathrm{C}$ reactiva es informada negativa. Se le observa muy irritable, rechaza la lactancia y presenta sangrado fácil en sitios de venopunción y punción capilar. Al sexto día presentó mayor distensión abdominal y la ecografía de abdomen reveló líquido libre en espacio intraabdominal y líquido libre en cavidad pleural derecha (Figura 1). El hemograma de control reveló leucopenia, incremento del hematocrito y plaquetopenia. La Prueba de diagnóstico rápido de dengue reveló Ag NS1 positivo (Standard diagnostic NS1 Ag strip, Corea), Ig M: negativo e Ig G positivo por ELISA captura, Tariki dengue (INS, Lima - Perú). Al séptimo día la fiebre cede, pero persiste distensión abdominal e incremento de la hepatomegalia, mayor plaquetopenia, mayor hemoconcentración reflejada por el incremento del hematocrito y persiste leucopenia (Tabla 1). Recibe tratamiento de soporte en la unidad de cuidados críticos neonatales y en los días sucesivos evoluciona favorablemente, reinicia alimentación oral por succión directa y se objetiva disminución de derrames serosos por reabsorción. Al décimo día el control ecográfico reveló ausencia de líquido libre en abdomen y en cavidad pleural, pero persiste hepatomegalia. La recién nacida se alimenta con fórmula recibiendo $170 \mathrm{~mL} / \mathrm{kg} / \mathrm{día}$, con buen flujo urinario y una curva de crecimiento en ascenso. A los 13 días es dada de alta con lactancia artificial. Posteriormente, el Laboratorio "Maxime Kuczynski" del Instituto Nacional de Salud en la ciudad de lquitos confirma la presencia de virus del dengue DEN-2 por técnica de PCR en tiempo real en una muestra de sangre periférica de la RN tomada al segundo día de enfermedad.
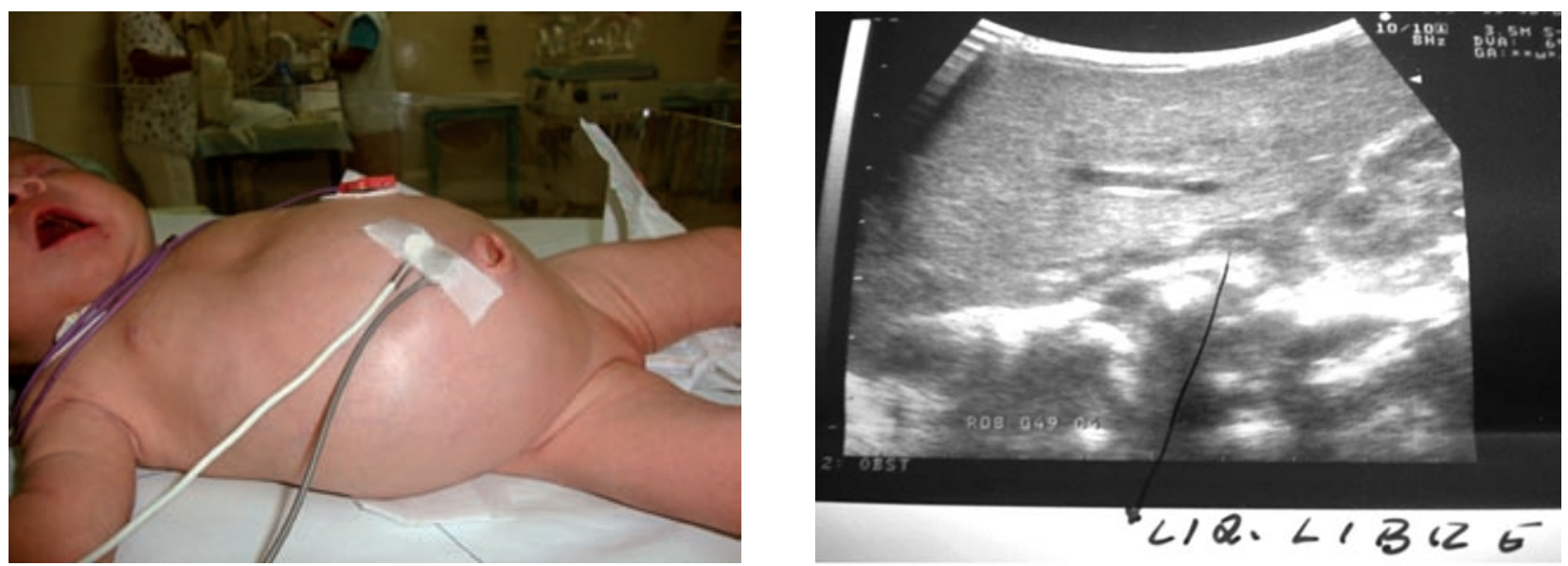

Figura 1. A. Recién nacida que en su quinto día de vida y segundo de enfermedad, cursa febril. Nótese la distensión abdominal con hepatomegalia de $4 \mathrm{~cm}$. B. Ecografía abdominal donde se destaca el líquido libre en cavidad peritoneal. 
Tabla 1. Resultados de exámenes de laboratorio según edad en días del neonato.

\begin{tabular}{|c|c|c|c|c|c|c|c|}
\hline \multirow{2}{*}{$\begin{array}{l}\text { Pruebas de } \\
\text { laboratorio }\end{array}$} & \multicolumn{7}{|c|}{ Edad en días } \\
\hline & 3 & 5 & 6 & 7 & 8 & 9 & 11 \\
\hline Hematocrito (\%) & 45 & & 48 & 52 & 53 & 47 & 47 \\
\hline $\begin{array}{l}\text { Leucocitos } \\
\left(/ \mathrm{mm}^{3}\right)\end{array}$ & 7800 & & 4900 & 4200 & 7000 & 103006 & 6300 \\
\hline Neutrófilos (\%) & 56 & & 67 & 32 & 30 & 60 & 62 \\
\hline Linfocitos(\%) & 44 & & 33 & 68 & 70 & 42 & 34 \\
\hline Monocitos (\%) & 0 & & 0 & 0 & 0 & 0 & 4 \\
\hline $\begin{array}{l}\text { Plaquetas } \\
\text { (x 103/ul) }\end{array}$ & 120 & & 87 & 40 & 50 & 133 & 140 \\
\hline BT (mg/dL) & & 14,8 & & 4,1 & & & \\
\hline $\mathrm{BD}(\mathrm{mg} / \mathrm{dL})$ & & 1,7 & & 0,5 & & & \\
\hline $\mathrm{BI}(\mathrm{mg} / \mathrm{dL})$ & & 13 & & 3,6 & & & \\
\hline $\begin{array}{l}\text { Glicemia } \\
\text { (mg/dL) }\end{array}$ & & 39 & & 41 & & & 63 \\
\hline
\end{tabular}

BT: bilirrubina total, BD: bilirrubina directa, BI: bilirrubina indirecta.

\section{DISCUSIÓN}

En el escenario epidemiológico de brote de dengue en la ciudad de lquitos, durante la temporada 2010 2011, reportamos el primer caso de dengue neonatal documentado en el Perú transmitido de una madre con dengue grave, confirmado por la detección de antígeno NS1 y de inmunoglobulina M específica para dengue ${ }^{(6)}$; el PCR en tiempo real negativo en la madre se explica porque la toma de muestra se hizo al décimo día de enfermedad, cuando la viremia transitoria ya había desaparecido.

En la revisión sistemática de Pouliot y col. (7) sobre dengue materno y desenlace de los productos de gestación, la muerte materna por dengue ocurrió en el $2,9 \%$ de una serie de casos de 137 madres y en ningún de 25 casos reportados aisladamente en la literatura, lo cual demuestra que la muerte materna por dengue es un evento poco frecuente. En nuestra paciente pudo haber influido el tiempo de gestación cuando desarrolla dengue, no haber sido diagnosticada de dengue previamente a la cesárea de urgencia, el serotipo probable de infección que puede corresponder al DEN2 genotipo III (variante asiática-americana) y posiblemente fallas en el sistema de salud y de referencias para manejar las complicaciones del síndrome de choque por dengue que desarrolló la madre. Estos autores recomiendan evitar procedimientos invasivos como cesáreas en pacientes con dengue grave por las complicaciones hemorrágicas presentadas ${ }^{(7)}$. Algunos reportes discuten la dificultad para diferenciar dengue grave de preclampsia, eclampsia y síndrome HELLP (anemia hemolítica, incremento de enzimas hepáticas y plaquetopenia); en estos casos son obligatorias las pruebas rápidas para diferenciar estos diagnósticos ${ }^{(8,9)}$.

La Organización Mundial de la Salud (OMS) en su Guía para el diagnóstico, tratamiento, prevención y control del dengue del año 2009, afirma que la trasmisión vertical del virus dengue se ha demostrado en el laboratorio pero casi nunca en el campo ${ }^{(6)}$. Según una reciente revisión sistemática se han descrito alrededor de 35 casos de transmisión vertical en el mundo ${ }^{(9)}$. Algunos reportes proceden de Venezuela ${ }^{(10)}$ y México ${ }^{(11)}$, en ambos casos el diagnóstico fue con determinación de Ig $\mathrm{M}$ y los recién nacidos descritos fueron dados de alta con evolución satisfactoria a los 12 días de nacidos. La transmisión vertical, con enfermedad en el neonato, también se ha descrito en las zonas tropicales donde el dengue es endémico como el sudeste asiático, India, Brasil, Ecuador, Colombia, Centro América y El Caribe ${ }^{(12-17)}$. En el otro extremo, se han descrito infecciones por dengue en gestantes en diversos periodos de la gestación, incluso en días cercanos al parto sin afectar al neonato y sin evidencias de infección vertical ${ }^{(18)}$.

Las manifestaciones clínicas en el recién nacido parecen no asociarse con la gravedad de la enfermedad materna, al tipo de parto o al estado de inmunidad previa para dengue ${ }^{(7)}$. Sin embargo, el tiempo de infección durante la gestación puede ser importante; la infección de la madre durante el periparto puede incrementar la probabilidad de enfermedad sintomática en el recién nacido, como sucedió en nuestro caso. Petdachai y col. ${ }^{(19)}$ describen la transmisión vertical de dengue en un neonato de Tailandia, que inicia sus manifestaciones a las 16 horas de nacido, demostrando, tanto en la madre como en el recién nacido, el virus del dengue serotipo 1 (DENV-1) mediante PCR. El inicio precoz de síntomas en este caso, sugeriría que la infección habría ocurrido en el útero, lo cual demuestra la trasmisión vertical. La RN del caso de Iquitos tuvo inmunoglobulina $M$ negativa y $G$ positiva, esta última probablemente transmitida por la madre, al sexto día de vida y al segundo día de enfermedad, lo cual demuestra que la transmisión fue reciente, probablemente durante la cesárea a través de la trasmisión de productos sanguíneos tanto de una forma percutánea como por contacto con mucosas durante las maniobras de parto ${ }^{(7)}$. Sin embargo, no se puede descartar la transmisión intraútero ya que días previos a la cesárea, la madre estaba en fase febril con elevada viremia, lo cual también se ha asociado con transmisión trasplacentaria ${ }^{(19)}$. Se descarta la transmisión vectorial intrahospitalaria porque los ambientes de cuidados neonatales son cerrados y no se han presentado otros neonatos afectados. 
Las manifestaciones clínicas descritas en dengue neonatal varían desde las formas asintomáticas hasta manifestaciones como trombocitopenia, hepatomegalia y formas graves con derrame pleural, ascitis, hemorragias e insuficiencia circulatoria y falla multiorgánica (7, 9-16). La mayoría de casos de dengue en fetos y en recién nacidos sobrevivieron sin secuelas posteriores ${ }^{(7,12)}$. La recién nacida presentó sus primeras manifestaciones al cuarto día de vida. Inicialmente presentó ictericia, por lo cual se pensó en un síndrome ictérico secundario a incompatibilidad ABO por lo que fue expuesta a fototerapia, con una rápida mejora, pero por desarrollar fiebre recibió cobertura con antibióticos de amplio espectro; la ictericia también ha sido descrita como síntoma inicial de dengue neonatal ${ }^{(10)}$. El cuadro febril en la paciente duró aproximadamente tres días y se asoció con cianosis, hipoglicemia, hepatomegalia, leucopenia con linfocitosis, trombocitopenia, proteína $\mathrm{C}$ reactiva negativa y extravasación de líquidos en pleura y abdomen, lo cual nos permitió alejar la posibilidad de sepsis por infección bacteriana y diagnosticar probable dengue grave en el neonato, que fue confirmado con la detección de Ag NS1 y posteriormente con PCR en tiempo real. A pesar de no contar con una unidad de cuidados intensivos neonatales, la recién nacida recibió tratamiento de soporte con adecuada hidratación y manejo del medio interno y el cuadro se autolimitó a partir del octavo día de vida. La mayoría de los neonatos con transmisión vertical reportados en la literatura tuvieron una evolución similar.

Es importante recalcar que en condiciones de un brote epidémico de dengue, las gestantes tienen mayor riesgo de desarrollar formas graves y hasta fatales, ello asociado, probablemente, a su estado transitorio de inmunosupresión ${ }^{(7,13)}$. En estos casos se debe sospechar de dengue y proceder al diagnóstico con pruebas rápidas en el mismo sitio de atención.

En conclusión, la revisión de bibliografía efectuada es consistente con la existencia de transmisión vertical de dengue, dependiendo del tiempo cuando se produce la infección materna, la gravedad de las manifestaciones en la madre y el tipo de parto. Posiblemente la cesárea contribuyó a la transmisión perinatal del virus dengue a la recién nacida. A partir de este caso se adoptó la política que toda gestante con sospecha de dengue se admitiera en el hospital para observación y manejo, a fin de prevenir casos fatales y la posibilidad de transmisión vertical. Los pediatras, médicos emergencistas y médicos del primer nivel de atención deben tener en cuenta las enseñanzas de este caso clínico para prevenir estos desenlaces. EI fortalecimiento de los servicios de salud de las zonas endémicas de dengue y del sistema de referencias es una necesidad en el país.

\section{AGRADECIMIENTOS}

Al señor Maximiliano Pérez Núñez padre del neonato, quien brindó todas las facilidades del caso para el presente reporte.

\section{Conflictos de Interés.}

Los autores declaran no tener conflictos de interés en la publicación del presente artículo.

\section{REFERENCIAS BIBLIOGRÁFICAS}

1. Phillips I, Need J, Escamilla J, Colon E, Sanchez S, et al. First documented outbreak of dengue in the Peruvian Amazon region. Bull Pan Am Health Organ 1992; 26: 201-207.

2. Morrison AC, Minnick SL, Rocha C, Forshey BM, Stoddard ST, et al. Epidemiology of Dengue Virus in lquitos, Peru 1999 to 2005: Interepidemic and Epidemic Patterns of Transmission. PLoS Negl Trop Dis 2010; 4(5): e670. doi:10.1371/ journal.pntd.0000670. Disponible en: http://www. plosntds.org/article/info\%3Adoi\%2F10.1371\%2Fjournal. pntd. 0000670

3. Ministerio de Salud. DIRESA-Loreto. Análisis de Situación de Salud de Loreto, 2007. Lima, MINSA;2008. Disponible en: http://diresaloreto.gob.pe/portal/index.php?option=com_co ntent\&view=article\&id=72\&ltemid=28

4. Instituto Nacional de Salud. En el Instituto Nacional de Salud se confirma la circulación de un nuevo linaje del virus dengue en Iquitos. Boletín Semanal Instituto Nacional de Salud. 2011;(4):1-5. Disponible en: http://www.ins.gob.pe/ insvirtual/images/boletin/pdf/BOLETIN042011.pdf

5. Oliveira M, Galvao Araujo J, Ferreira OJ, Ferreira D, Lima D, et al. Two lineages of dengue virus type 2, Brazil. Emerg Infect Dis. 2010;16(3):576-78. Disponible en: http:// www.cdc.gov/eid/content/16/3/pdfs/576.pdf

6. World Health Organization. Dengue Guidelines for diagnosis, treatment, prevention and control. Geneva: WHO; 2009. Disponible en: http://whqlibdoc.who.int/ publications/2009/9789241547871_eng.pdf

7. Pouliot Sh, Xiong X, Harville E, et al. Maternal Dengue and Pregnancy Outcomes. A Systematic Review. Obstet Gynecol Surv. 2010;65:107-18.

8. Chawanpaiboon S, Titapant V, Puthavathan $P$, et al. Antiplatelet transfusion in dengue hemorrhagic fever during pregnancy: a case report. Siriraj Hosp Gazette. 1998;50:964-966.

9. Chye JK, Lim CT, Ng KB, et al. Vertical transmission of dengue. Clin Infect Dis. 1997;25:1374-1377.

10. González G, Guerra A, Malvé L y Pérez P. Dengue neonatal, a propósito de un caso. Archivos Venezolanos de Puericultura y Pediatría. 2001; 64(4): 219-222.

11. Castellanos, J, Hernández, $P$, Arellano, B, Newton, O.A. y Espinoza, F. Reporte de un caso de dengue neonatal. Bol Med Hosp Infant Mex. 2006; 63:202-206. 
12. Sirinavin $S$, Nuntnarumit $P$, Supapannachart $S$, Boonkasidecha S, Techasaensiri C, Yoksarn S. Vertical dengue infection: case report and review. Pediatr Infect Dis. 2004;23: 1042-1047.

13. Tan PC, Rajassingam G, Devi S, Omar SZ. Dengue infection in pregnancy: prevalence, vertical transmission, and pregnancy outcome. Obstet Gynecol. 2008;111:1111-7.

14. Maroun SL, Marliere RC, Barcellus RC, Barbosa CN, Ramos JR, Moreira ME. Case report: vertical dengue infection. J Pediatr (Rio J). 2008; 84:556-9.

15. Restrepo BN, Isaza DN, Salazar CL, Ramírez JL, Upegui GE, Ospina M y Ramiírez R. Dengue en el Embarazo. Efecto en la Madre y en el feto. Epidemiol Infect. 2005; 133,503-507.

16. León RR, Muñoz MR, Soler E, Parissi A, Méndez G. Dengue durante el embarazo. Comunicación de casos. Ginecol Obstet Mex. 2007;75:687-90.

17. Fernández R, Rodríguez $T$, Borbonet $F$, Vázquez $S$, Guzmán MG, Kouri G. Study of the relationship denguepregnancy in a group of cuban-mothers. Rev Cubana Med Trop. 1994;46:76-8.
18. Phongsamart W, Yoksan S, Vanaprapa N, and Chokephaibulkit K. Dengue Virus Infection in Late Pregnancy and Transmission to the Infants. Pediatr Infect Dis J. 2008;27:500-504.

19. Petdachai W, Silaon J, Nimmannitya $S$ and Nisalak A: Neonatal Dengue infection. Report of Dengue Fever in a 1-Day-old infant. Southeast Asian J Trop Med Public Health. 2004;35:403-407.

Correspondencia: Hermann Silva Delgado.

Dirección: Brasil 343 Iquitos, Perú.

Teléfono: 965-613367.

Correo electrónico: silvahermann@hotmail.com

\section{Consulte las ediciones anteriores de la} Revista Peruana de Medicina Experimental y Salud Pública en

\section{www.scielosp.org}

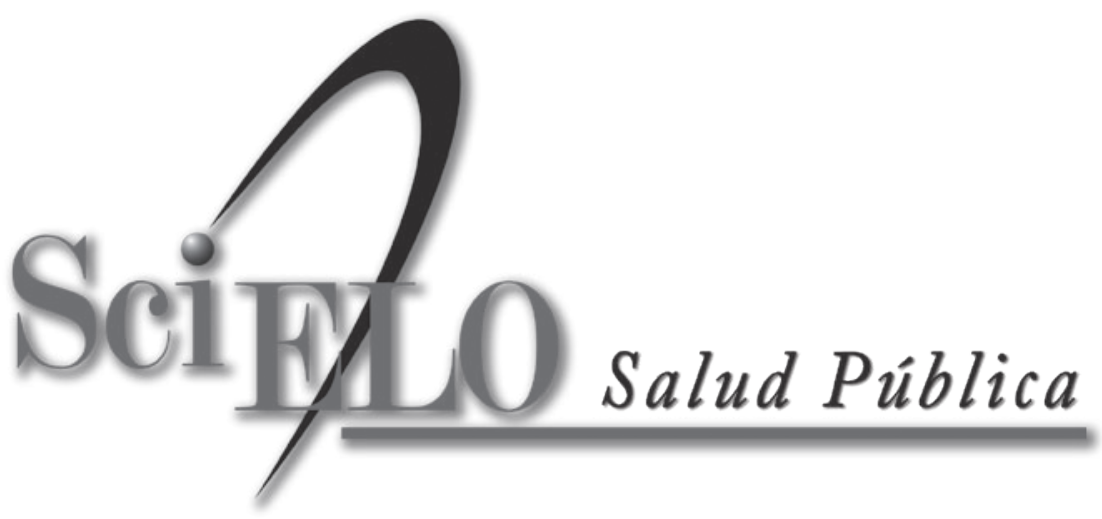

